\title{
Práticas de leitura: o uso das redes sociais como recurso de ensino-aprendizagem no ensino médio
}

\author{
Laís Costa Santos ${ }^{\mathrm{i}}$ \\ Ingrid Bomfim Cerqueira ${ }^{\text {ii }}$ \\ Vanessa de Carvalho Cayres Pamponét ${ }^{i i i}$
}

\section{RESUMO}

No presente artigo, estão apresentadas as investigações sobre de que maneira podem acontecer as práticas de leitura através do uso das redes sociais, bem como uma proposta interdisciplinar de sequência didática. Tal investigação se justifica dada a urgência em se compreender processos de ensino-aprendizagem que auxiliem o aluno a construir um conhecimento mais próximo de sua realidade. A metodologia adotada foi baseada na pesquisa-ação e realizada no Instituto Federal Baiano. A análise dos resultados obtidos permite mostrar que o aluno precisa ser estimulado a se posicionar criticamente diante da diversidade de informações e conteúdos correspondentes às redes sociais, desse modo é sugerida uma sequência didática interdisciplinar com o gênero "Memes" como alternativa, ao mesmo tempo em que se reconhece o amplo viés de possibilidades de outras propostas.

Palavras-chave: Leitor crítico; Multiletramentos; Tecnologias digitais.

\begin{abstract}
In this article, we seek to investigate how reading practices can happen through the use of social network, while we also present an interdisciplinary proposal of didactic sequence. Such an investigation is justified given the urgency to understand teachinglearning processes that help students build knowledge that is closer to their reality. Thus, we adopted the action research methodology at the Federal Institute of Bahia. The results showed that students need to be encouraged to take a critical position in the face of the diversity of information and content corresponding to social networks. It is expected, with this study, to point out an interdisciplinary work with the genre "Memes"
\end{abstract}

\footnotetext{
i Especializanda em Educação Científica e Cidadania pelo Instituto Federal de Educação, Ciência e Tecnologia Baiano - Campus Uruçuca, Licenciada em Letras pela Universidade Estadual de Santa Cruz (UESC). E-mail: costalais@ hotmail.com. ORCID: https://orcid.org/0000-0003-4492-8030.

ii Mestra em Letras: Linguagens e Representações pela Universidade Estadual de Santa Cruz (UESC), Professora da área de Linguagens no Instituto Federal de Educação, Ciência e Tecnologia Baiano Campus Uruçuca. E-mail: ingrid.cerqueira@ifbaiano.edu.br. ORCID: https://orcid.org/0000-0003-41825618.

iii Doutora em Genética e Biologia Molecular pela Universidade Estadual de Santa Cruz - UESC. Professora Efetiva do Instituto Federal de Educação, Ciência e Tecnologia Baiano - Campus Uruçuca. Email: vanessa.pamponet@ifbaiano.edu.br. ORCID: https://orcid.org/0000-0003-4374-8249.
} 
as an alternative, while recognizing the wide range of possibilities of other proposals, which are more effective and motivating for students, when they prioritize multiliteracies.

Keywords: Critical reader; Multiliteracies; Digital technologies.

\section{INTRODUÇÃO}

Pensar e discutir a inserção das Tecnologias de Comunicação e Informação (TIC) no ambiente educacional é um desafio que exige (re)pensarmos as variadas práticas pedagógicas, quando estas estimulam a formação de leitores conscientes, competentes e que saibam se posicionar diante dos inúmeros textos que leem. Assim, ao considerar a forte presença das tecnologias digitais no cotidiano de grande parte dos alunos, em decorrência da circulação de textos cada vez mais multimodais, faz-se necessário refletir sobre o ensino e a formação do leitor crítico.

Dessa forma, um dos grandes desafios enfrentados pela escola é o de formar sujeitos críticos, pensantes, capazes de participar com competência da sociedade em que estão inseridos. Capazes de agir diante de uma leitura em busca de significado, na medida em que expõem um ponto de vista sobre os diversos assuntos com que se deparam, principalmente no contexto atual, onde ocorre a conexão com o mundo virtual. Por isso, acreditamos que esse trabalho pode ser realizado através dos recursos disponibilizados pelas redes sociais, visando a interação entre alunos e professores, a fim de contemplar as novas práticas de leitura que estão surgindo neste contexto.

No entanto, apesar de estudiosos da área da linguagem, como Coscarelli (2009), Rojo (2012) e Santaella (2004), buscarem formas de utilizar métodos pedagógicos de leitura e escrita em ambientes virtuais, os alunos ainda apresentam dificuldades para atribuir sentidos às informações veiculadas, e assim, construir o seu posicionamento crítico. Diante do exposto, surgiram as questões norteadoras desta pesquisa: Como as redes sociais podem ser utilizadas enquanto recurso no ensino e aprendizagem de estudantes do ensino médio? Em que medida o uso das redes sociais pode contribuir nesta formação e despertar o interesse dos estudantes para realização de atividades de leitura? 
Estabelecer como ponto de partida a discussão das questões propostas neste artigo é importante, uma vez que nos conduz a uma reflexão sobre o papel do professor na formação do cidadão crítico. Além disso, é necessário discutir e compartilhar práticas pedagógicas que propiciem a formação de leitores capazes de desenvolver o senso crítico e potencializar a construção de sentidos, de modo que se ultrapasse o pensamento tradicional de que ler é apenas uma mera decodificação de ideias. Ademais, é sabido que com a tecnologia o leitor mudou, a leitura passou a ter um formato mais fluido, dinâmico e efêmero. Para compreendermos essa nova configuração que invade o ambiente escolar, é importante a inserção dos ambientes virtuais como recursos de ensino-aprendizagem.

Nesse sentido, vinculamos a essa pesquisa, alguns dos referenciais teóricos dos estudos de Rojo (2012) com a pedagogia dos multiletramentos. De igual forma, nos valemos dos pressupostos de Dias e Aragão (2014); Xavier e Aragão (2013) que retratam a potencialidade da utilização da tecnologia digital como proposta metodológica de ensino. Os estudos de Solé (1998) e Raimundo (2009) se revelam fundamentais para a compreensão do trabalho pedagógico voltado à formação do leitor crítico.

Desse modo, o objetivo geral do estudo foi investigar de que maneira pode acontecer o ensino da leitura através do uso das redes sociais no ensino médio e como isso pode auxiliar o aluno a construir seu próprio conhecimento. Para tanto, a pesquisaação traçou objetivos específicos na tentativa de sensibilizar os alunos a usarem as redes sociais como recurso no processo ensino-aprendizagem.

De forma semelhante, a identificação das estratégias para formar leitores críticos dentro e fora do contexto escolar foi essencial para justificar a importância das práticas de multiletramentos com vistas a propor o ensino da leitura de maneira mais eficiente. Enquanto produto final, a partir da pesquisa-ação realizada, pensamos em sugerir uma Sequência Didática (SD) que assegure a relevância do diagnóstico levantado, de modo que funcione enquanto suporte de aplicação da teoria à prática escolar.

Por fim, a pesquisa-ação se dedica a discutir a formação do leitor crítico em ambientes virtuais, além de promover a elaboração de práticas de multiletramentos com o intuito de serem mais efetivas e motivadoras. 


\title{
1. FUNDAMENTAÇÃO TEÓRICA
}

\subsection{As redes sociais como ferramenta motivadora no ensino-aprendizagem da leitura}

Com o avanço das Tecnologias de Comunicação e Informação, é preciso repensar as práticas de leitura em ambientes virtuais, de forma a torná-las uma ferramenta capaz de levar o aluno a construir o conhecimento. Outro ponto é que tal ferramenta o auxilie a exercer a cidadania nos diversos contextos sociais, permitindo-lhe o desenvolvimento de habilidades e competências que contribuem para a interdisciplinaridade de saberes.

De acordo com a Base Nacional Comum Curricular (BNCC), oficializada em dezembro de 2017, deve-se considerar que devido à multiplicação das Tecnologias de Comunicação e Informação, bem como a facilidade de acesso a elas, os estudantes estão dinamicamente inseridos na cultura digital, a qual tem proporcionado mudanças sociais relevantes nas sociedades contemporâneas. Tal documento salienta que:

\begin{abstract}
Os jovens têm se engajado cada vez mais como protagonistas da cultura digital, envolvendo-se diretamente em novas formas de interação multimidiática e multimodal e de atuação social em rede, que se realizam de modo cada vez mais ágil. Por sua vez, essa cultura também apresenta forte apelo emocional e induz ao imediatismo de respostas e à efemeridade das informações, privilegiando análises superficiais e o uso de imagens e formas de expressão mais sintéticas, diferentes dos modos de dizer e argumentar característicos da vida escolar (BRASIL, 2017, p. 61).
\end{abstract}

Compreende-se, então, que é necessário orientar os jovens a apropriar-se das ferramentas digitais com consciência, estimulando neles a criticidade e a reflexão aprofundada, com o intuito de que o aluno seja capaz de filtrar as informações presentes na multiplicidade de ofertas digitais. Quanto a isso, é importante destacar o pensamento de Xavier e Aragão:

O mundo globalizado traz a necessidade de estar inserido dentro desse processo, não apenas dominando as Tecnologias de Informação e Comunicação (TIC), mas utilizando de forma crítica e adequada os variados gêneros textuais que lhes são oferecidos na prática social. Se pensarmos na importância que as instituições de ensino têm para formação do cidadão crítico e participativo, perceberemos que é papel também da escola apresentar 
condições para que o estudante possa utilizar essas ferramentas tecnológicas, abrangendo os âmbitos que se constituem como imprescindíveis para a sua vida social, como as relações pessoais, profissionais e interpessoais (XAVIER; ARAGÃO, 2013, p. 50).

Nessa linha de raciocínio, a escola deve aproveitar as potencialidades da tecnologia digital, utilizando-a adequadamente e de forma a abarcar os diversos gêneros textuais. Ainda na mesma clave, Pretto e Assis (2008) afirmam que no campo da educação, a incorporação dessas tecnologias não pode se dar simplesmente como ferramentas adicionais ou como animadoras dos tradicionais processos de ensinoaprendizagem. As tecnologias devem ser entendidas como elementos geradores das mudanças que estamos vivendo, o que nos leva a crer que a educação necessita ultrapassar as fronteiras do próprio campo educacional.

A propósito disso, Rojo (2012) enfatiza que com a chegada mais rápida e intensa das tecnologias, de novas práticas de leitura e de escrita que condizem com os acontecimentos atuais, no que se refere aos textos mulltissemióticos circulantes, a escola deve oportunizar gêneros que se adequem a essa realidade. Além disso, se há mudança nas tecnologias e nos textos contemporâneos, é imprescindível uma mudança no sistema educacional de uma ponta a outra, visto que serão cada vez mais presentes os letramentos demandados por tais transformações.

Nesse sentido, não é de se surpreender que, com a inserção das tecnologias digitais e das mudanças no paradigma da leitura, novas exigências sejam impostas. Professores e alunos precisam estar preparados, como explica Belluzo (2011, p. 43): "Há uma transformação dos textos, contextos, nos públicos e modos de ler. Nessa dimensão, ler é a condição de estar no mundo, criando-o outra vez". Ainda, complementa que:

\begin{abstract}
A grande questão emergente é que agora, a quantidade de informação exige o desenvolvimento de novas habilidades e competências para a capacidade de escolha, orientação de busca, ordenação pessoal de dados. Assim, somente os verdadeiros iniciados como leitores poderão navegar pelos labirintos das bibliotecas virtuais com conforto e independência. Esta é a chamada "alfabetização do Século XXI", que vai além do letramento ou literacia tradicional que envolve a leitura, escrita, expressão oral, cálculo matemático e resolução de problemas. Exige uma formação de leitores que não se limita a uma mera decodificação ou reconhecimento de palavras, mas um aprendizado que permite desenvolver competências para a atribuição de sentido àquilo que se lê e a compreensão crítica da realidade para o exercício da cidadania (BELLUZO, 2011, p. 46).
\end{abstract}


Aqui percebe-se que os leitores devem desenvolver novas habilidades de leitura, a fim de ter autonomia para "navegar" com tranquilidade e liberdade pelos labirintos das redes. Desse modo, é imprescindível a formação de leitores que possam não apenas decodificar símbolos linguísticos, mas compreender as informações, se posicionar de forma crítica e reflexiva, com consciência da cidadania.

Sobre esse aspecto, Freire (1989, p. 7) aborda que "a compreensão crítica do ato de ler, é aquela que não se esgota na decodificação pura da palavra escrita ou da linguagem escrita, mas que se antecipa e se alonga na inteligência do mundo". Dessa maneira, a compreensão crítica do texto envolve a percepção das relações entre o texto, o contexto e os conhecimentos prévios do leitor.

As redes sociais permitem mais que a simples interação, a colaboração, como afirma Rojo (2012). Elas atuam como mediadoras de aprendizagem, proporcionando a interação entre alunos e professores, visto que a tecnologia se tornou uma forte aliada no processo de ensino. Para Zacharias (2016), o surgimento de formas de comunicação como as redes sociais implica transformações no processo de criação e recepção dos textos, por permitir ampla exploração de aspectos como a interatividade, a hipertextualidade e a multimodalidade, que demandam habilidades de leitura específicas. Nesses espaços, leitor e autor interagem de maneira intensa, e os espaços de produção passam a ser cada vez mais interativos e colaborativos (LORENZI; PÁDUA, 2012).

A leitura no meio digital, de acordo com Garcia et al. (2012), não acontece de forma linear como nos textos tradicionais, obedecendo uma sequência fixa e havendo uma ideia de um todo previamente existente. Nesse âmbito, os textos adquiriram uma nova dinâmica, requerendo do leitor uma posição mais ativa, de modo a realizar escolhas e tomar decisões. As redes sociais, por sua vez trazem tal dinamicidade em torno de imagens, vídeos, textos que se apresentam de forma rápida e atrativa.

Dessa forma, a fim de tornar a leitura mais prazerosa e significante para os alunos, é de suma importância que a escola incorpore os recursos disponibilizados pelas redes sociais, além de proporcionar aos educandos o "contato com diferentes gêneros, suportes e mídias de textos escritos" (LORENZI; PÁDUA, 2012, p. 36), levando-os a perceber os efeitos de sentido produzidos pelas novas mídias e como podem ser críticos, autônomos e produtivos (GARCIA et al., 2012). 


\section{MULTILETRAMENTOS: NOVAS PROPOSTAS PARA A FORMAÇÃO DO LEITOR CRÍTICO NA ERA DIGITAL}

Diante das múltiplas possibilidades de uso das linguagens e das variedades linguísticas, as redes sociais surgem como espaço de ensino-aprendizagem de língua portuguesa e das demais disciplinas que compõem o currículo do ensino médio. Explorar os diversos gêneros textuais multimodais (propaganda, notícias, letra de música, artigo de opinião, "Memes", receita, relatos, charge, crônica, etc, que se misturam ao mundo de imagens, cores, sons e movimentos) "permite a ampla e rica abordagem das condições de produção de enunciados, situações de comunicação e relação dialógicas que lhe são constitutivas” (LORENZI; PÁDUA, 2012, p. 39).

Todavia, nos ambientes virtuais têm surgido novos gêneros, como o chat, os gifs, os podcasts, dentre outros trazidos para/pela internet. (DIAS ET AL, 2012). Dessa maneira, cabe à escola criar novas possibilidades de leitura, buscar estratégias a fim de propiciar ao educando um novo direcionamento em relação ao uso dessa rede social.

Nesse sentido, Dias et al. (2012) discutem as modificações nas práticas de letramento baseadas em atividades de leitura e escrita advindas da inserção e uso das novas tecnologias, "os textos combinam imagens estáticas (e em movimento), com áudio, cores, links, sejam nos ambientes digitais ou na mídia impressa" (p. 76), o que passa a exigir do leitor outras modalidades utilizadas, expandindo a noção de letramentos para múltiplos letramentos.

A leitura no contexto da BNCC (2017) é vista nesse sentido mais amplo, abrangendo não apenas o texto escrito, mas também imagens estáticas (foto, pintura, desenho, esquema, gráfico, diagrama) ou em movimento (filmes, vídeos etc.) e ao som (música), que estão presentes em muitos gêneros digitais. Para Lorenzi e Pádua (2012), os multiletramentos levam em consideração essa multimodalidade que está presente nas redes sociais, bem como a multiplicidade de significações e contextos/culturas. Além disso, esses autores abordam a formação de leitores proficientes aos multiletramentos, o que precisa levar em consideração o caráter multimodal dos textos e a multiplicidade de sua significação: 
O texto, tal como o conhecemos e utilizamos, é extrapolado; livros didáticos "engessados" e práticas descontextualizadas dão lugar à hipermídia; a capacidade de criação é desafiada; ler e escrever deixa de ser o fim, para ser o meio de produzir saberes e, além disso, compartilhá-los numa relação dialógica. As tecnologias devem ser objeto de ensino e não somente ferramenta de ensino (LORENZI; PÁDUA, 2012, p. 39).

Ao aproveitar o potencial de comunicação das redes sociais, os professores possuem alternativas para estabelecer novas práticas didático-pedagógicas que promovam a aprendizagem, a interação e o compartilhamento de significados que podem ser disseminados por todos. Dias e Aragão (2014), corroborando com Rojo (2012), falam da proposta dos multiletramentos, cujo conceito difere daquele de letramento, pois vai além da noção de diversidade das práticas letradas. O processo formador da pedagogia dos multiletramentos possibilita aos alunos lidarem com usos de linguagem em ambientes diversos, visando à consciência social e política, apontando para dois tipos específicos de multiplicidade em nossas sociedades: a multiplicidade cultural das populações e a multiplicidade semiótica que compõe os textos dos quais se informa e se comunica.

Considerando as análises aqui realizadas, quanto mais o aluno vivenciar práticas de multiletramentos que fazem parte de seu cotidiano, se apropriando do texto em diferentes dimensões e a ele se entregar, mais crítico, autônomo e reflexivo será. Desse modo, é fundamental que a escola utilize as tecnologias como aliadas no processo educativo, de maneira que estimule aos educandos o uso mais democrático das tecnologias.

Segundo Danielle Brito (2010), é por intermédio da leitura que podemos formar cidadãos críticos, uma condição fundamental para o exercício da cidadania. Na proporção em que ocorre a prática consciente, o indivíduo passa a entender melhor o significado das inúmeras vozes que se manifestam no debate social, é capaz de refletir, ter suas opiniões e de se pronunciar com a própria voz, tomando consciência de todos os seus direitos e aprendendo a lutar por eles. Como Lois (2010) observa, se a prática da leitura não faz parte da vida do indivíduo, o desenvolvimento da cidadania fica comprometido, uma vez que através da leitura pode aumentar o repertório crítico. "Sem a crítica, o poder de julgamento fica limitado e a capacidade de intervenção e inserção cultural, também” (LOIS, 2010, p. 19). 


\section{PRÁTICAS DE LEITURA: UMA PERSPECTIVA INTERDISCIPLINAR}

Ensinar a ler nunca foi uma questão tão simples e "envolve a presença de um leitor ativo que processa e examina o texto. Também implica que sempre deve existir um objeto para guiar a leitura, em outras palavras sempre lemos para algo, para alcançar alguma finalidade" (SOLÉ, 1998, p. 22). Desse modo, é preciso propor aos alunos a utilização de estratégias que lhes permitam interpretar e compreender com autonomia os textos em seus diferentes meios de circulação. Para que essa tarefa de ajudar os alunos a compreenderem os propósitos implícitos e explícitos da leitura seja bem sucedida, é necessário o envolvimento de todos os professores, independente de seu campo de atuação.

Entretanto, no que se diz respeito à importância do papel da escola na formação de leitores, os Parâmetros Nacionais Curriculares (PCN) salientam que, para formar leitores competentes, a escola tem de orientar e encontrar meios que incentivem a prática constante de leitura, sensibilizar quanto à importância do ato de ler, por meio de uma prática pedagógica estimulante e participativa. Deve-se ainda levar em consideração o pensamento de Raimundo (2009), ao enfatizar que se não houver uma preocupação em incentivar o gosto do aluno pela leitura, será muito difícil que ele possa se tornar um leitor crítico e consciente. A preocupação maior deve ir muito além de formar apenas leitores, mas sim, leitores críticos.

Dentro dessa perspectiva, segundo o estudo proposto por Maia (2011, p. 26), “a atitude de um leitor crítico é a de um sujeito curioso diante do texto e da vida". Para a referida autora, "ser um leitor crítico ou mesmo um pensador crítico significa buscar o que não é evidente, é procurar respostas para perguntas que ainda não foram feitas, ou seja, é pensar com autonomia e criar sua própria trilha do conhecimento" (MAIA, 2011, p. 43-44). O leitor crítico é capaz de ler e interpretar informações, fazer inferências, tomar decisões e atuar na sociedade (GOES, 2015).

É sabido que todos os professores, das diferentes áreas do conhecimento, fazem uso da leitura. De acordo com Sauthier e Prochnow (2003), na perspectiva interdisciplinar, o ensino da leitura não é responsabilidade exclusiva da disciplina de língua portuguesa, "os outros professores não são meros informadores, e sim, formadores e também responsáveis pelo ensino da leitura" (p. 192). Assim, os trabalhos 
significativos em todas as disciplinas devem criar condições de aprendizagem, em que o aluno consiga estabelecer a conexão entre texto e contexto, levando em consideração o seu conhecimento de mundo.

\section{METODOLOGIA}

A fim de compreendermos de que maneira podem acontecer as práticas de leitura através do uso das redes sociais, e como isso pode auxiliar o aluno a construir seu próprio conhecimento e exercer seu papel social, a presente pesquisa foi desenvolvida por meio de pesquisa bibliográfica, intervencionista, baseada na pesquisaação e com abordagem qualitativa para a análise de dados. Segundo Cervo, Bervian e da Silva (2007, p. 61), a pesquisa bibliográfica "constitui o procedimento básico para os estudos monográficos, pelos quais se busca o domínio do estado da arte sobre determinado tema”.

Em relação à pesquisa qualitativa, Minayo (2001) afirma que ela trabalha com significados, motivos, crenças, valores e atitudes que não podem ser reduzidos à operacionalização de variáveis, ou seja, ela responde a questões muito específicas. Nessa perspectiva, Ludke e André (2013) abordam que a pesquisa qualitativa tem o ambiente natural como sua fonte de dados e o pesquisador é o seu principal instrumento.

A presente pesquisa-ação teve como participantes dezesseis alunos, de ambos os gêneros, compreendidos na faixa etária de dezessete a vinte e um anos, todos matriculados numa turma de segunda série do ensino médio, do Instituto Federal de Educação, Ciência e Tecnologia Baiano, situado no município de Uruçuca, Bahia. O critério utilizado para escolha da turma dos participantes aconteceu de forma aleatória, levando em consideração apenas o Ensino Médio, visto que esses alunos possuem uma autonomia maior com o uso das redes sociais.

A análise qualitativa desses dados foi apresentada de forma descritiva, buscando aporte teórico nos estudos de Rojo (2012) com a pedagogia dos multiletramentos. Nos postulados teóricos de Dias e Aragão (2014) encontramos informações fundamentais para uma análise que considera a utilização da tecnologia digital como proposta metodológica nas práticas de leitura. Para o desenvolvimento da pesquisa-ação foi empregada a técnica dos questionários semiabertos. Assim, de acordo com Gil (2008), 
podemos entender o questionário como um conjunto de questões que são respondidas por escrito pelo pesquisado a fim de traduzir os objetivos específicos da pesquisa em itens bem escritos, além de garantir o anonimato.

Por fim, pensamos no desenvolvimento de uma proposta didática cuja temática central seja a Sustentabilidade, a fim de que, com o trabalho interdisciplinar com o gênero "Memes", se possa potencializar o surgimento de leitores críticos bem como reconhecer o amplo viés de possibilidades de propostas didáticas. Ao privilegiarem os multiletramentos, tais propostas se tornariam mais efetivas e motivadoras para os discentes.

A metodologia adotada compreendeu o que foi proposto por Dolz, Noverraz e Schneuwly (2004), dividindo-se nas seguintes etapas: a apresentação da situação, a produção inicial, os módulos e a produção final, que corresponde a 10 aulas. O público previsto abrange os alunos do ensino médio. Pensando em uma proposta pedagógica interdisciplinar, foi escolhida a temática Sustentabilidade para o trabalho com os "Memes", o qual permite ao aluno refletir sobre suas atividades cotidianas, o que pode provocar novas formas de enxergar o mundo, despertar pensamentos críticos e atitudes éticas.

\section{RESULTADOS E DISCUSSÃO}

Os questionários foram elaborados com o objetivo de obter um levantamento das impressões dos alunos em relação à proposta da pesquisa-ação, de como as redes sociais podem contribuir no ensino-aprendizagem da leitura e identificar a relação desses alunos com o uso das redes sociais. Para tanto, objetivava obter informações sobre o tempo utilizado nas redes sociais, em quais locais os alunos costumam mais usá-las e quais são as mais utilizadas.

Observamos que a maioria dos alunos acredita que as redes sociais podem contribuir positivamente para o desenvolvimento da competência leitora e considera interessante o seu uso para fins educacionais, conforme é possível observar na análise das respostas apresentadas no questionário, exibida no Quadro 01. 
Quadro 01 - Demonstração parcial das respostas dos alunos (transcrição literal) referente à questão 11 do questionário aplicado.

\section{Questão 11: Com relação à leitura, você acredita que as redes sociais poderiam} contribuir para incentivar a prática leitora? Por quê?

Aluno 1: Sim, porque há um interesse maior em relação a algo que o meio passa.

Aluno 2: Sim, porque assim podemos ler aquilo que é do nosso gosto.

Aluno 3: Sim, porque acaba levando a leitura, mesmo que seja apenas frases influencia a leitura, a descobrir coisas novas.

Aluno 4: Sim, é um mecanismo de acesso rápido a inúmeros conteúdos que podem ser dificilmente encontrados em materiais bibliográficos.

Aluno 5: Acredito que sim, pois em algumas redes sociais acontece a divulgação de textos.

Aluno 6: Sim. Já que todo mundo tem acesso às redes sociais, creio que ela seria uma ferramenta de grande ajuda no incentivo à leitura.

Aluno 7: Sim. Por estarmos horas e horas nas redes sociais e no celular, nos deparamos com inúmeros textos interessantes que contribuem para nossa formação social, além de nos mantermos informados com as notícias de nível mundial.

Aluno 8: Sim. Porque tem muita gente que não lê livro, revistas, mas está sempre atualizado das notícias etc.

Aluno 9: Sim. Porque precisamos ler para fazer uso das redes sociais.

\section{Fonte: A autora}

Em contrapartida, alguns alunos relataram que as redes sociais podem atrapalhar o processo de leitura, dado que, com as inúmeras novidades disponíveis o tempo todo, eles podem perder o foco, isto é, perder a concentração na leitura do texto, na sua estrutura e nos possíveis sentidos. Zacharias (2016) cita os fatores negativos devido à inserção das tecnologias digitais como perceptíveis nas práticas de leitura, visto que a emergência de textos com linguagens múltiplas e multimodais as altera, assim como interfere no processamento de informação e na construção dos significados.

Diante disso, é importante que o aluno saiba "navegar" pelos ambientes virtuais, buscando usá-los conscientemente e selecionando informações relevantes para os seus propósitos. Além disso, devem saber localizar informações disponíveis nos ambientes virtuais, fazer inferências, reconhecer efeitos de sentido, dentre outras habilidades, como afirma Coscarelli (2009).

Em seus estudos, Santaella (2004) trata dos novos leitores que surgem diante da evolução tecnológica das redes sociais e dos aparelhos móveis, o que exige novas habilidades de leitura em ambientes virtuais. A autora batiza um outro tipo de leitor, o 
ubíquo, que "deriva do imersivo e brotou tão logo se tornou usuário dos dispositivos móveis os quais lhe proporcionaram a possibilidade de acessar as redes e se comunicar com seus pares e mesmo ímpares de qualquer lugar e em quaisquer momentos” (p. 18). É o tipo de leitor que tem a capacidade de ler e transitar nas redes sociais, entre a mesclagem de textos, imagens, sons, vídeos e links.

É sabido que os jovens, na atualidade, têm passado boa parte do seu tempo em frente a uma tela de smartphone, devido às inúmeras informações e à diversidade de conteúdos interessantes das redes sociais. Desta maneira, foi questionado o que mais leem (jornais, revistas, livros, textos que circulam nas redes sociais etc.). O que se observou foi que o conteúdo mais lido pela turma são os textos nas redes sociais. Segundo Kenski (2012), as redes de comunicações com sua gama infindável de informações, trazem novas e diferenciadas possibilidades para que os indivíduos possam se relacionar com os conhecimentos e aprender.

Para o questionamento acerca da acessibilidade às redes sociais e do tempo diário que passam as utilizando, observamos que todos os alunos entrevistados têm acesso à internet e o tempo diário que passam conectados foi maior que duas horas, corroborando com os estudos de Dias e Aragão (2014) ao ressaltar como as redes sociais digitais atraem um número cada vez maior de usuários. Contudo, nem todos sabem lidar com tantas informações que as Tecnologias de Comunicação e Informação oferecem a todo instante, e, por vezes, o acesso às redes sociais não acontece de forma equilibrada. Sobretudo, elas não devem ser vistas apenas como lugar de comunicação e interação, mas também de aprendizagens.

Desse modo, em busca de ressignificar as aulas e visando a uma aprendizagem colaborativa, propomos que as práticas de leitura aconteçam a partir da pedagogia dos multiletramentos, aliados ao uso das redes sociais, mais especificamente, uma Sequência Didática (SD) com enfoque no desenvolvimento da competência leitora e habilidades de leitura, utilizando o WhatsApp. Os questionários revelaram que o WhatsApp é o aplicativo mais utilizado pelos alunos da turma. Desse modo, optamos por trabalhar com esse aplicativo de comunicação social e com o gênero "Memes". Lemos e Aragão (2017, p. 86) pontuam que "práticas textuais contemporâneas, comuns em redes sociais e no WhatsApp, como os memes, podem ser trabalhadas na perspectiva dos multiletramentos", proporcionando uma aprendizagem mais significativa. 
De acordo com Dolz, Noverraz e Schneuwly (2004, p. 82), "a sequência didática é um conjunto de atividades escolares sistematizadas, em torno de um gênero textual oral ou escrito". Além disso, busca oportunizar a mudança e a promoção dos alunos ao domínio dos gêneros e das diversas situações de comunicação. Sobre esse aspecto, Dias et al. (2012) argumentam que uma SD bem delimitada pode proporcionar o desenvolvimento da capacidade comunicativa dos alunos no processo ensinoaprendizagem, permitindo que desenvolvam habilidades de comunicação e os auxiliando a conhecer, explorar e produzir os diversos gêneros que estiverem sendo estudados. Nessa perspectiva, propomos uma sequência didática que se dinamiza da seguinte forma:

1. Apresentação da situação - apresentar aos alunos o contexto de produção, o gênero "Memes" que será abordado, para que eles compreendam a situação de comunicação e desenvolvam as atividades de linguagem. Nesse momento, será criado o grupo de WhatsApp administrado pelo professor da turma. É preciso trabalhar a capacidade de usar as tecnologías de forma crítica, autônoma e cidadã dos alunos;

2. Produção escrita inicial - será solicitado aos alunos que postem no grupo do WhatsApp gêneros diversos (charges, tirinhas, entrevistas, reportagens, notícias, "Memes", links, dentre outros) sobre o tema Sustentabilidade. Os alunos irão ler e analisar as postagens, e então comentarão, através de um pequeno texto ou através dos recursos disponibilizados no WhatsApp (emojis, gifs, figurinhas, áudios), os sentidos possíveis, promovendo o diálogo. Os alunos farão a primeira versão dos "Memes", com o tema Sustentabilidade, levando em consideração o local em que vivem;

3. Módulos de ensino - desenvolvidos a partir dos seguintes procedimentos:

a) Ensinar a estrutura do gênero "Memes" e analisar suas marcas linguísticas;

b) Atividade interdisciplinar: Eixo temático - Ecologia;

4. Produção final - os "Memes" da produção inicial diagnosticados serão retomados pelos alunos, que farão a avaliação e a reescrita.

O primeiro passo da SD é a apresentação da situação aos alunos, e tem por finalidade fornecer "as informações necessárias para que conheçam o projeto comunicativo visado e a aprendizagem de linguagem que está relacionado" (DOLZ; 
NOVERRAZ; SCHNEUWLY, 2004, p. 84). Nessa etapa, é importante que os alunos percebam a importância do gênero e saibam a temática que será trabalhada.

O segundo passo é a produção inicial, em que os alunos tentam elaborar uma primeira versão do gênero. Ainda que as primeiras produções não apresentem todas as características do gênero que será abordado, os alunos conseguem responder à situação dada e o professor pode avaliar as dificuldades encontradas pela classe e, assim, modular e refinar a sequência didática de acordo com as necessidades reais dos alunos da turma.

O terceiro passo se trata de trabalhar os módulos de ensino segundo Dolz, Noverraz e Schneuwly (2004). Nessa etapa, os alunos aprendem a falar sobre o gênero, adquirem um vocabulário, uma linguagem técnica, que, ao mesmo tempo, se torna comunicável a outros, o que é imprescindível, pois permite uma atitude reflexiva na construção do próprio conhecimento.

Por fim, a sequência é finalizada com uma produção final que permite que o aluno entenda a importância do aperfeiçoamento de sua escrita inicial a partir do que aprendeu. Após o referido processo de reflexão sobre o gênero, o professor retomará com os alunos o percurso diante das várias situações de comunicação estudadas ao longo dos módulos anteriores.

Elaboramos uma SD para os alunos do Ensino Médio $\left(1^{\circ}, 2^{\circ}\right.$ ou $3^{\circ}$ ano), visando a estrutura do Instituto Federal de Educação, Ciência e Tecnologia Baiano (IF Baiano), situado no município de Uruçuca - Bahia, mas a SD pode ser adaptada de acordo com a realidade de cada escola. O campus possui acesso à rede wi-fi, além de disponibilizar um laboratório de informática. É importante pontuar que, embora haja muitas pesquisas sobre como utilizar as redes sociais no contexto escolar, fizemos uma proposta de trabalho interdisciplinar. Pretendemos demonstrar que é possível desenvolver uma sequência de atividades com leitura articulada entre outras disciplinas, estimulando a criatividade, a criticidade e a utilização dos recursos digitais.

Assim, por meio desta pesquisa buscou-se formar leitores críticos, contribuindo para que o aluno do Ensino Médio desenvolva sua capacidade argumentativa. Além disso, se faz necessário que o aluno seja sensibilizado a utilizar as redes sociais digitais, adquirindo um novo olhar para a tecnologia em sala de aula. Dessa maneira, o presente 
artigo abre possibilidades para o trabalho com leitura em ambientes digitais no contexto escolar.

\section{CONSIDERAÇÕES FINAIS}

A presente pesquisa permitiu repensar a contribuição das práticas pedagógicas na formação de um leitor crítico. Além de enfatizar a importância das práticas de multiletramentos, visando ao ensino da leitura de maneira mais eficiente. Em razão disso, antes de sugerir um caminho para potencializar nosso objetivo geral, foi preciso mergulhar nas fontes de uma vasta fundamentação teórica devido à relevância e atualidade de tal temática.

Dessa maneira, fundamentado na pedagogia dos multiletramentos, compreendese que mesmo reconhecendo a necessidade de o sistema educacional, de modo geral, incorporar os recursos disponibilizados pelas redes sociais, é extremamente necessário buscar estratégias para orientar o direcionamento em relação ao uso desses ambientes e das habilidades de novas leituras. O aluno precisa ser estimulado a se posicionar criticamente diante da diversidade de informações e conteúdos correspondentes às redes sociais.

Procuramos trazer neste artigo uma sequência didática com a temática Sustentabilidade para o trabalho com os "Memes", a fim de promover a leitura crítica e ampla de textos multissemióticos. Nesse ínterim, as reflexões sobre as práticas de leitura e o uso das redes sociais como recurso de ensino-aprendizagem culminam em uma proposta de trabalho que visa à formação crítica do aluno, direcionando-o para que ele esteja habilitado a agir e interagir a partir do contexto em que estiver inserido.

\section{Referências}

BELLUZO, Regina Célia Baptista; FERES, Glória Georges. "Tecnologias e a formação de leitores: Desafios na sociedade contemporânea". In: BARROS, Daniela Melaré Vieira et al. (org). Educação e tecnologias: reflexão, inovação e práticas. 1.ed. Lisboa: 2011. p. 42-71.

BRASIL. Base Nacional Comum Curricular. Brasília: MEC, 2017. Disponível em: http://basenacionalcomum.mec.gov.br/images/BNCC_EI_EF_110518_versaofinal_site. pdf. Acesso em: 30 jul. 2019. 
BRITO, Danielle Santos de. A importância da leitura na formação social do indivíduo. Revela, n. 8, ano IV, p. 1-35, jun. 2010.

CERVO, Amado L.; BERVIAN, Pedro A.; SILVA, Roberto da. Metodologia científica. 6. ed. São Paulo: Pearson Prentice Hall, 2007.

COSCARELLI, Carla Viana. Texto e Hipertexto: procurando o equilíbrio. Linguagem em (Dis)curso, Palhoça, v. 9, n. 3, p. 549-564, set./dez. 2009.

DIAS, Iky Anne; ARAGÃO, Rodrigo Camargo. Multiletramentos, facebook e ensino de inglês nas escolas. Revista Calidoscópio, v. 12, n. 3, p. 380-389, set/dez 2014.

DIAS, M. V. A. et.al. "Minicontos Multimodais: reescrevendo imagens cotidianas". In: ROJO, R.; MOURA, E. (Org.). Multiletramentos na escola. São Paulo: Parábola Editorial, 2012. p. 75-94.

DOLZ, Joaquim; NOVERRAZ, Michéle; SCHNEUWLY, Bernard. "Sequências didáticas para o oral e a escrita: apresentação de um procedimento". In: SCHNEUWLY, Bernard; DOLZ, Joaquim. Gêneros orais e escritos na escola. Trad. e org. ROJO, Roxane; CORDEIRO, Glaís Sales. São Paulo: Mercado de Letras, 2004. p. 95-128.

FREIRE, Paulo. A importância do ato de ler: em três artigos que se completam. São Paulo: Cortez, 1989.

GARCIA, Cintia B. et al. "Projet(o) arte: uma proposta didática". In: ROJO, R.; MOURA, E. (org.). Multiletramentos na escola. São Paulo: Parábola Editorial, 2012. p. 123-146.

GIL, Antonio Carlos. Como elaborar projetos de pesquisa. 4. ed. São Paulo: Atlas, 2008.

GOES, Aline de. Tornar o aluno crítico: enunciado (in)questionável no discurso da educação matemática escolar. 189 f. 2015. Dissertação (mestrado) - Universidade Federal de Santa Catarina, Centro de Ciência Físicas e Matemáticas. Programa de Pós Graduação em Educação Científica e Tecnológica. Florianopólis - SC, 2015.

KENSKI, V. M. Educação e tecnologias: o novo ritmo da informação. Campinas: Editora Papirus, 2012.

LEMOS, Laís; ARAGÃO, Rodrigo. Multiletramentos e WhatsApp na Aprendizagem de inglês no Ensino Médio. Polifonia, Cuiabá-MT, v. 24, n. 35/1, p. 73-94, jan.-jun.2017.

LOIS, Lena. Teoria e prática da formação do leitor: leitura e literatura na sala de aula. Porto Alegre: Artmed, 2010.

LORENZI, Gislaine Cristina Correr; PÁDUA, Tainá-Rekã Wanderley de. "Blog nos anos iniciais do fundamental I: a reconstrução de sentido de um clásico infantil". In: 
ROJO, R.; MOURA, E. (org.). Multiletramentos na escola. São Paulo: Parábola Editorial, 2012. p. 35-54.

LUDKE, Menga; ANDRE, Marli E. D. A. A Pesquisa em educação: abordagens qualitativas. 2 ed. Rio de Janeiro: E.P.U., 2013.

MAIA, Janicleide Vidal. A leitura crítica a partir da interpretação de charges jornalísticas. 2011. 220 f. Dissertação (Mestrado) - Universidade Federal do Ceará, Centro de Humanidades, Programas de Pós Graduação em Linguística, Fortaleza Ceará, 2011.

MINAYO, Maria Cecília de Souza (org.). Pesquisa Social. Teoria, método e criatividade. 18 ed. Petrópolis: Vozes, 2001.

PRETTO, Nelson L.; ASSIS, Alessandra. "Cultura digital e educação: redes já!". In: PRETTO, Nelson. L.; SILVEIRA, Sérgio. A. (org.). Além das redes de internet, diversidade cultural e tecnologias do poder. Salvador: EDUFBA, 2008. p. 75-84.

RAIMUNDO, Ana Paula Peres. A mediação na formação do leitor. Anais do $3^{\circ}$ CELLI - Colóquio de Estudos Linguísticos e Literários, Maringá, p. 107-117, 2009.

ROJO, R. Pedagogia dos Multiletramentos: Diversidade cultural e de linguagens na escola. In: ROJO, R.; MOURA, E. (org.). Multiletramentos na escola. São Paulo: Parábola Editorial, 2012, p. 11-32.

SANTAELLA, Lucia. Navegar no ciberespaço: o perfil cognitivo do leitor imersivo. São Paulo: Palus, 2004.

SAUTHIER, Ângela Maria Lorenzoni; PROCHNOW, Ana Lúcia Cheloti. O ensino da leitura numa perspectiva interdisciplinar: uma proposta de aplicação. Disciplinarum Scientia / Artes, Letras e Comunicação, Santa Maria, v. 4, n. 1, p. 185-201, 2003.

SOLÉ, I. Estratégias de leitura. 6. ed. Porto Alegre: Artmed, 1998.

XAVIER, Adriana Castro; ARAGÃO, Rodrigo Camargo. Facebook como Proposta Metodológica Interdisciplinar: Diálogo entre o Ensino de LP e LE. Litterata - Revista do Centro de Estudos Portugueses Hélio Simões, v. 3, p. 50-69, 2013.

ZACHARIAS, Valéria Ribeiro de Castro. "Letramento digital: desafios e possibilidades para o ensino". In: COSCARELLI, C. V. (org.) Tecnologias para aprender. São Paulo: Parábola Editorial, 2016. p. 15-26. 